\title{
РАЗВИТИЕ РЫНКА ФИНАНСОВЫХ УСЛУГ ВЬЕТНАМА В ЦИФРОВОЙ ЭПОХЕ
}

\author{
(c) 2020 Ле Хунг Нинь \\ аспирант кафедры «Логистика и маркетинг» \\ Финансовый университет при Правительстве Российской Федерации, Россия, Москва \\ E-mail: lehungninh.tueba@gmail.com
}

Идет 4-я промышленная революция, которая сильно влияет на социально-экономическую жизнь Вьетнама. Финансово-бюджетный сектор в целом и рынок финансовых услуг в частности, считается одним из наиболее прибыльных секторов, но одновременно сильно пострадает от этой революции. Оценивая ситуацию с применением новых финансовых технологических решений на рынке финансовых услуг Вьетнама, анализируя направления развития этого рынка в ближайшем будущем, в статье представлены некоторые рекомендации с технической точки зрения для поддержки управления, развития финансовых рынков безопасным, прозрачным и эффективным способом.

Ключевые слова: финансовые услуги, информационные технологии, рынок, FinTech, мобильный платеж, бизнес, экономической.

\section{Описание}

В финансовом секторе в 2019 году по состоянию на 31.12.2019 года доходы государственного бюджета оценивались в 1.539,4 трлн. донгов [5], что превышает прогноз на 9,1\% и обеспечивает ресурсы для экономического развития, социального обеспечения, национальной обороны и безопасности. К концу 2019 года государственный долг составлял около 55\% ВВП, сохраняя сильную тенденцию к снижению с 63,7\% ВВП в 2016 году [5]. Эти положительные результаты внесли значительный вклад в устойчивость бюджета и безопасность государственного долга. В последнее время на рынке финансовых услуг во Вьетнаме произошли значительные изменения, которые сыграли важную роль в стабилизации макроэкономики, повышении конкурентоспособности экономики и стимулировании устойчивого экономического развития. На финансовый рынок в 2019 году приходилось 323\% ВВП [5].

В контексте сильной промышленной революции 4.0 (Индустрия 4.0) финансово-бюджетный сектор в целом и рынок финансовых услуг в частности оцениваются как одна из областей, на которые большое влияние оказывает все более популярное использование приложений финансовых технологий (финтех) в финансовых транзакциях экономики.

Согласно прогнозу PwC, к 2020 году будет около 28\% традиционных бизнесов в банковской сфере и сфере платежей и $22 \%$ традиционных бизнесов в сфере страхования и управления активами, которые были сильно затронуты, мо- гут быть заменены приложениями финансовых технологий. Появление и устойчивое развитие цифровых валют также является большой проблемой для управления рынком финансовых и валютных услуг нынешних правительств.

Использованию научно-технических достижений промышленной революции 4.0 в поддержке управления и развития рынка финансовых услуг уделяется особое внимание Партией, Правительством, Министерством финансов Вьетнама.

Тенденции развития финансовых технологий во Вьетнаме

Во Вьетнаме финтех является относительно новой сферой, в которой около 40 предприятий предоставляют услуги в следующих областях: предоставление платформ, платежных решений, мобилизация общественного капитала, личные финансы и т.д.

Финансовые технологии используются для описания новой тенденции в банковской и финансовой индустрии. Проще говоря, финтех - это применение науки и технологий в финансово-банковской сфере. Спрос на услуги по снабжению финтеха составляют банки, страховые компании, традиционные финансовые институты, потребители и обычные предприятия.

Компании финтех в настоящее время предоставляют услуги в различных областях, таких как банковские технологии, платежи, управление финансами, цифровые валюты и т.д. с разнообразными продуктами, такими как элек- 
тронные кошельки, технология распределенной бухгалтерской книги на платформе блокчейна, онлайн-коммерция B2C, mPOS и т.д.

По сути, можно классифицировать услуги, которые предоставляют компании финтех, по видам услуг: финансовые услуги (мобилизация капитала от сообщества, кредит и т.д.); управление активами (инвестиционные социальные сети); рекомендации по автоматизации; управление личными финансами; инвестиционные и банковские услуги; платежные услуги (альтернативные способы оплаты, безопасность); другие услуги (страхование, гарантии, другие технологические решения).

Финтех принес с собой волну стартапов в финансово-банковской сфере, в которой ранее требовался обильный капитал. Это также приводит к разнообразию состава продуктов, что также затруднит управление.

Тем не менее, при правильном использовании, финтех может принести определенные преимущества, такие как: изменение канала распространения продукта, упрощение продукта для потребителей; простой анализ поведения клиента; сокращение рабочей силы, что снижает затраты организации; сокращение рисков ошибок; экономия средств, снижение цен, скидки на продукцию.

Наряду с развитием Индустрии 4.0 все больше и больше потребителей используют продукты и услуги финтеха. Доли клиентов, использующих продукты и услуги финтеха для оплаты, перевода денег, личных финансов, личных зай- мов и сбережений, составляют 84\%, 68\%, 60\%, $56 \%$ и $49 \%$ соответственно (Рисунок 1 ).

Вьетнам также стал свидетелем успешного года в привлечении инвестиций в технологии. Количество успешных сделок по привлечению капитала увеличилось с 8\% всего региона в 2018 году до 9\% в 2019 году. Между тем, общий капитал в сделках также увеличился с 1\% до 3\% [6].

Платформа, предоставляющая платежные решения, в настоящее время доминирует в количестве компаний, составляя 58\% от общего числа компаний, работающих в секторе финтеха. Общая сумма транзакций с использованием цифровых платежных решений, по оценкам, возрастет с 7.259 млн. долл. США в 2017 году до 8.523 млн. долл. США в 2019 году. Для сектора личных финансов общая оценочная сумма транзакций выросла с 16 млн. долл. США в 2017 году до 58 млн. долл. США в 2019 году. В области краудфандингового финансирования общая сумма транзакций, согласно оценкам, выросла с 0,4 млн. долл. США в 2017 году до 0,8 млн. долл. США в 2019 году [6].

Решения для развития рынка финансовых услуг Вьетнама

Чтобы в полной мере использовать возможности «Индустрии 4.0» для эффективного развития рынка финансовых услуг Вьетнама, в ближайшее время необходимо сосредоточиться на реализации следующего содержания:

Bo-nервых, изучить и разработать финансовую стратегию до 2030 года в соответствии с направленностью развития цифровой экономики,

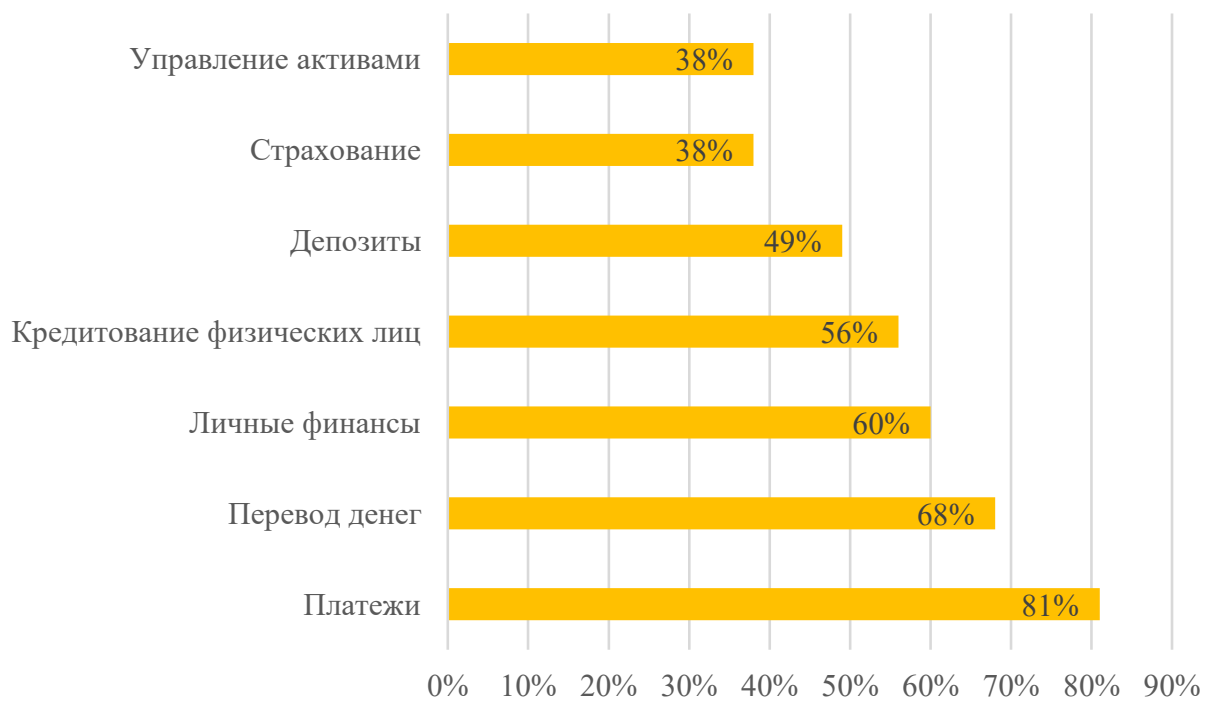

Рисунок 1. Доля клиентов, использующих продукты финтеха [6] 
создать основу для реализации инновационной деятельности в сфере государственного управления, поддержки и содействия развитию частных лиц и организаций, работающих на рынке. Кроме того, необходимо срочно исследовать, построить и развернуть ряд ключевых проектов, создать прорыв, способствовать развитию финансового рынка: проект обновления процесса и профессии финансового сектора в соответствии с цифровой экономической моделью; схема построения государственной учетной и бюджетноинформационной системы; проект реструктуризации фондового рынка и страхового рынка до 2020 года и ориентация на 2025 год и т.д.

Во-вторых, разработать инновационную среду тестирования, как для поддержки финансовых компаний в исследованиях, разработке и тестировании новых финансовых решений, так и для того, чтобы исследователи и политики имели ранний доступ, прогнозировали новые тенденции в области финансовых технологий, и с тех пор, предложили соответствующие правовые рамки для поддержки развития финансовых технологических компаний. Однако для эффективного функционирования финансовых услуг необходимо одновременно координировать и возглавлять три агентства, которые играют важ- ную роль в развитии рынка финансовых услуг: Министерство финансов, Государственный банк и Министерство планирования и инвестиций.

B-третьих, создать и развить рабочую силу, которая обладает профессиональными навыками и навыками в области информационных технологий, и знает о приложениях, разработанных на основе новых технологий, используемых в финансовых услугах. В то же время укреплять сотрудничество, обмен и изучение опыта со странами и международными организациями.

B-четвертых, построить развитие цифровой инфраструктуры, обеспечить информационную безопасность системы, защиту личной информации, а также усилить координацию обмена информацией между агентствами по надзору за рынком финансовых услуг стран, чтобы своевременно выявлять и предотвращать деятельность по отмыванию денег, а также «чистить» рынок финансовых услуг.

На пути к финансовому рынку Вьетнама для безопасной, прозрачной и эффективной работы в контексте «Индустрии 4.0» требуется активное участие всех лиц и организаций, действующих в этой области. В частности, органы государственного управления должны играть тектоническую роль, активно регулировать деятельность рынка.

\section{Библиографический список}

1. Ashenafi, F. The Relationship Between Technology and Financial Inclusion: Cross-Sectional Evidence/ F. Ashenafi, D. Makina// Extending Financial Inclusion in Africa. - 2019.- P. 211-230.

2. Alfred, S. Mobile financial services and financial inclusion: Is it a boon for savings mobilization?/ S.Alfred, T. Maureen, W. Maureen// Review of Development Finance. - 2017. - № 7.- P. 29-35.

3. Przychodzen, $W$. Green information technologies practices and financial performance - The empirical evidence from German publicly traded companies/W. Przychodzen, G. Fernando, P. Justyna// Journal of Cleaner Production.2018. - № 201.- P. 570-579.

4. Shubhasis, D. Dynamic linkages between gold and equity prices: Evidence from Indian/ D. Shubhasis, S. Aravind// financial services and information technology companies, Finance Research._-2018. — № 25. - P 41-46.

5. Официальный сайт Управление общей статистики Вьетнама [Электронный ресурс].- Режим доступа https://gso.gov.vn/default.aspx?tabid=621 \&ItemID=19558

6. Официальный сайт PricewaterhouseCoopers [Электронный pecypc].- https://www.pwc.com/gx/en/industries/ financial-services/assets/pwc-global-fintech-report-2019.pdf 